\title{
Illustrating the Anthropological Text: Drawings and Photographs in Franz Boas' The Social Organization and the Secret Societies of the Kwakiutl Indians (1897)
}

\author{
Camille Joseph
}

Franz Boas was an American anthropologist who played a major role in the development of modern anthropology in the twentieth century. Boas was born in Germany and started his scientific career as a physicist before he chose to dedicate himself to the field of ethnography. He left Germany in 1886 to study the Indian tribes of the Northwest Coast of Canada, among which were the Kwakiutl Indians who lived on Vancouver Island. Boas eventually settled in New York and became assistant curator of ethnology at the American Museum of Natural History (1895-1905). In 1897, he published his first monograph on the ceremonials of the Kwakiutl Indians, entitled The Social Organization and the Secret Societies of the Kwakiutl Indians. ${ }^{1}$ This monograph was published as a report for the United States National Museum based in Washington, D.C., which had been created under the auspices of the Smithsonian Institution, a scientific institution co-founded by the American government in the 1840 s to promote knowledge. The volume is an account of Boas' numerous field trips to British Columbia between the years 1886 and 1891 and then again in 1894. It was during this last trip that Boas decided to have photographs taken in order to illustrate the monograph he had already planned to write (Jacknis, 1984:36).

During the several field trips he made among the Indians of British Columbia, Boas collected a large number of specimens both for the National Museum and for other institutions, as well as images (both drawings and photographs). The Social Organization strikes at first glance as a bewildering mix of images representing artefacts, masks, totem poles, architectural plans, ceremonies and ritualistic events, "portraits" and outdoor scenes. The volume and intricacy of the images within it serve to provide a full description of a particular ceremonial - the winter ceremony. This focus sets the publication apart and gives it a unique standing among Boas' other works: never would he come closer to writing a complete ethnographical account, nor would he ever again use so

1 Hereafter The Social Organization, to be abbreviated so.

(C) CAMILLE JOSEPH, 2015 | DOI 10.1163/9789004270848_013

This is an open access chapter distributed under the terms of the Creative Commons AttributionNoncommercial 3.o Unported (CC-BY-NC 3.0) License. 
many illustrations (with the exception of Primitive Art, published in 1927). The 1897 report also provides a precious insight into Boas' various skills as an ethnographer in the field; he was able to learn native languages, to note down songs and music, to draw sketches, and to work with photographers (or even on occasion to take photographs himself).

The Social Organization is a very heavy volume of texts and images that Boas meticulously collected or had his informants collect. However, Boas never fully explained his use of the different kinds of ethnographic data. We are therefore bound to look into the ways he gathered, published and organized this diverse and complex array of raw data. A close examination of The Social Organization's layout, for example, provides one of the few ways in which we can understand Boas' position regarding the relatively new medium of photography and the way in which it could be used by the ethnographer. It appears that Boas successfully and quite uniquely combined a long tradition of scientific illustration with the modern approach of fieldwork ethnography, relying on photography and images to gather data. These images were a precious source of ethnographic information once the ethnographer had left the field. They were also a means of collecting stories and texts from the Indians themselves, illustrating the interaction that existed between text and image. In this article, I would like to analyze the status of these images as "illustrations" and to examine their position within the scientific narrative. First, I will argue that in order to understand the nature of these images, one should acknowledge that it was not uncommon at this time for reports such as Boas' to contain large numbers of images and that this can be seen as a reflection of the scientific standards set by North American institutions such as the Smithsonian in Washington. Second, many drawings can be found in the monograph that are reminiscent of a tradition in archaeological illustrations: drawings and photographs do not have the same status within the text. But more importantly, and this will be my final point, it is necessary to take into account the theoretical importance given to the native text and the fact that language, according to Boas, was the first and foremost expression of a culture.

\section{An Illustrated Report}

As noted previously, the illustrations found in The Social Organization are numerous and varied. If we consider only the drawings and photographs, and exclude the music sheets, we find a total of 266 illustrations for a 350-page publication, a ratio of more than one image to every two pages. The images are catalogued in the list of illustrations found at the end of the book and fall into two categories, the "plates" ( 51 in total) and the "text figures" ( 215 in total). The 
"text figures" are line drawings printed with text, and the "plates" are those images which have been printed separately and then inserted into the publication. This distinction reveals one of the chief drawbacks of photographic and photomechanical reproductions: unlike woodcuts, photographs could not at the time be printed on the sheet with type. Because of this technological constraint, photographs (reproduced in half-tone or in paintings) are all found among the plates (40 photographs) and appear on full pages. The iconography of The Social Organization is then not only plentiful but also diverse in terms of format, techniques and styles.

As noted above, the diversity and profusion of images was not rare in other North-American publications of the time, whether for scientific or commercial purposes (Marr, 1990). Government reports ${ }^{2}$ such as the ones published under the auspices of the Smithsonian Institution, which was a strong advocate and purchaser of images, combined different kinds of illustrations: maps, topographical drawings, sketches, engravings from photographs, paintings, etc. The introduction of photography in government surveys emphasized the demands and widened the uses and practices of images for scientific purposes, although photographs and photographically-based illustrations had been an expected component of U.S. government reports since 1875 (Sandweiss, 2002). For instance, the four Great Surveys, sent to the untamed regions of the American West in the late $1860 \mathrm{os}$, were conducted by teams of explorers who collected artefacts, and biological and geological specimens, and who either made images for themselves or commissioned professional painters, draftsmen, and photographers to do so on their behalf. Explorers were in great need of "visual" images; they felt that words were often unable to depict the wonders of the American West. The inventions of emulsion-coated film in the 1880 s and of Kodak's "hand camera" in 1890 multiplied the number of pictures that professional anthropologists and explorers could take on any given trip (Prins, 2004: $510){ }^{3}$ The camera also played an important role in securing visual representation of materials that ethnographers could not bring back with them to their museums. Photographs therefore provided accurate documentation of a world doomed to disappear. Anthropologists relied on pictures not only to collect, preserve and later study Native American cultures, but also to display their findings to the American public: the founders of American anthropology believed in the use of images as the basis for the educational mission of a science of mankind (Hinsley, 1981: 100).

2 For example, Caroline Lehni numbers 260 illustrations for 400 pages in Major John W. Powell's Canyons of the Colorado (1895). See C. Lehni (2006) 80.

3 On the vast amount of photographs (over 300o) taken during the Jesup North Pacific Expedition under the supervision of Boas, see Kendall and Mathé (1997) 7 . 
As a scientist who trained in cartographic and topographic drawing and in anthropometric measurements while he was studying in Berlin in the 1880 s, Franz Boas was able to use these sketches as scientific data and illustrations (Cole, 1983: 14). This is particularly visible in the geological drawings and maps reproduced in the report of his first field trip among the Inuit of Baffin Island (The Central Eskimo, 1885). However, to my knowledge, Boas did not use his own drawings in The Social Organization but had drawings made from his own sketches by professional artists such as George T. Emmons, Rudolf Weber or Emily Carr. Also, Boas learned how to use a camera in Berlin in 1882 and was not adverse to using photography. He made a wide use of the camera for anthropometric and craniometric measurements and he was also very active in collecting pictures of the native cultures he came in contact with. This appears in his correspondence with his friend and informant, George Hunt (1854-1933), a Kwakiutl Indian who became an assistant for many ethnographers and for Franz Boas in particular: in several letters, Boas asks Hunt to provide photographs of specific scenes or artefacts. But photographs did not completely take the place of drawings. Neither the invention of photography and its relative availability at the end of the nineteenth century, nor the wide-spread use of photography by most anthropologists at the turn of the twentieth century, produced a shift in Boas' methods. ${ }^{4}$ His prime concern remained the careful scientific study of the culture, rather than utilising the latest technological medium at his disposal.

\section{Drawings and Photographs}

Although Boas used photography as early as the 188 os, photographs did not become the privileged mode of illustration in his publications or the ones he supervised. Indeed the papers issued from the Jesup North Pacific Expedition, edited by Franz Boas between 1896 and 1926, reveal, as Michael Oppitz notes, "a beautiful balance between drawing and photography." (Oppitz, 2001: 121). The publications contained photographs by the authors, drawings, and indig-

4 I will only mention in passing the generously illustrated book of Sir Baldwin Spencer and P.J. Gillen, The Native Tribes of Central Australia, published in 1899. There are 119 photographs in the work, which is far more than would have been contained in other ethnographic monographs at the time. The success of the book is due to the distinction between these photographs which were taken outdoors, and other contemporary photographs which were taken in a studio. They are of a remarkable quality, and, as Peterson noted, they formed the first accessible and substantial corpus of ceremonial photographs from Australia (Peterson 2006). 
enous sketches. Therefore, once we acknowledge the technical difficulties which limited the direct reproduction of photographs, it is remarkable that Boas continued to make great use of a more conservative, illustrative medium such as drawing long after photography had been adopted by anthropologists. Yet did these images have the same status as photographs in terms of their scientific validity? We could suggest that drawings and photographs, since they offered differing "representations" of their subject matter, were both of use to an anthropologist.

The classification of illustrations found in The Social Organization shows that drawings are preferred to photographs when representing an object or artefact because they enable multiple views of the same object or artefact concurrently. One "illustration" can offer two or three different views of the same object. More importantly, it can highlight one detail of a specific artefact by selecting it and zooming in on it, or by omitting a part of the object to emphasize another. Text images represent selective and didactic perspectives: a synthetic and realistic view on the one hand and a complementary view representing only the outline of the object or the design painted on it on the other hand (Figure 11.1). As a consequence, a drawing seems to give a better idea of the volume and design of the objects.

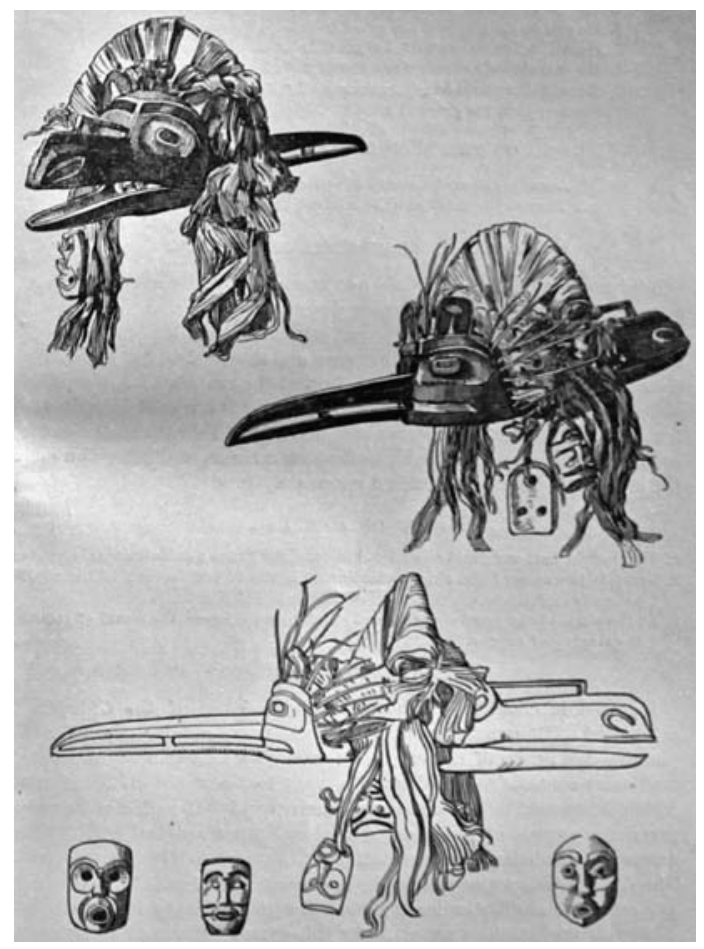

FIGURE 11.1

Figure 127 of The Social Organization represents three different views of the double-head mask of the Na'naqualitl, a dancer of the winter ceremonial. The figure shows two reverse- synthetic and realisticviews and a third, complementary view. The drawings of the mask's outline, while lacking in volume and materiality, is more precise as to the way the two masks are attached to one another. The smaller heads hanging from the mask are isolated at the bottom and therefore appear more clearly. 


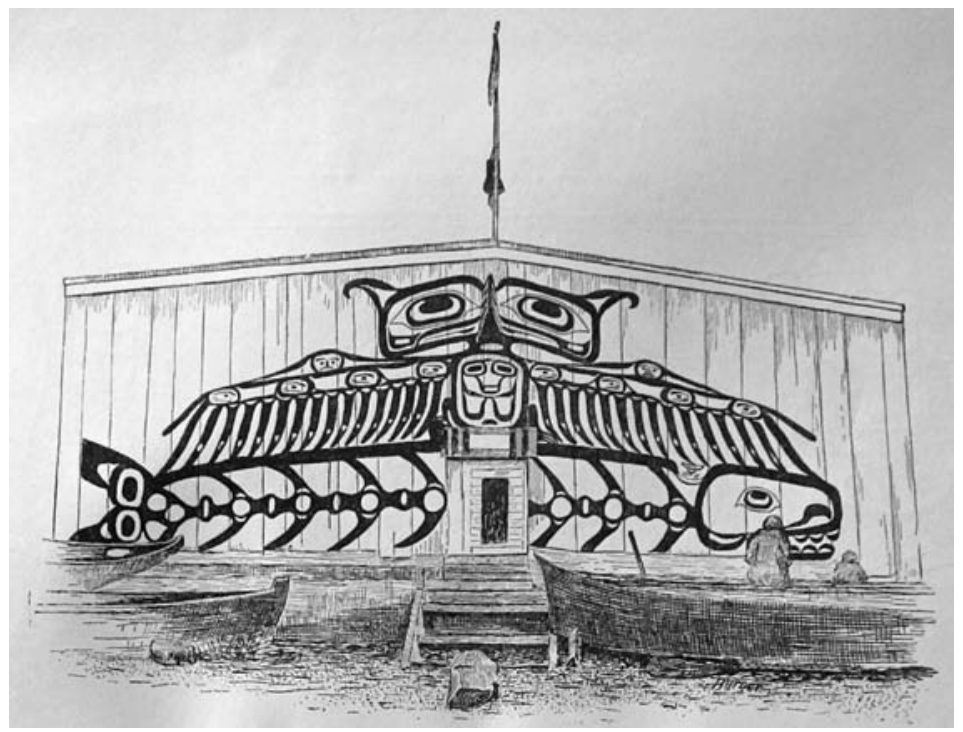

FIGURE 11.2 Figure 18 of The Social Organization represents the House front of the clan Gigilqam in the village of Nimkish. It is captioned "From a photograph." The painted motif of the house front appears distinctively. The presence of the two canoes on the beach and the two small human figures on the right hand side of the façade reinforces the large dimensions of the building and of the painting itself.

Following a tradition of archaeological illustration, Boas was well aware of the ability of drawings to explain and demonstrate: drawings provide a highly detailed view of the object to the reader which his/her own eyes fail to see. One example is particularly striking regarding the appreciation of drawings in a conflicting visual context. At one point in his report, Boas mentions a house located in a Kwakiutl village. The house front, it is said, had been painted and Boas provides the corresponding illustration with text figure $\mathrm{n}^{\circ} 18$ : a realistic figuration of a house and, in the centre of the front, the bold black design (Figure 11.2).

In the text preceding and following the illustration, Boas writes:

Fig. 18 shows the house front of the clan Gigilqam of the Nimkish. It represents the thunderbird lifting a whale, which is its food, from out of the water. According to the clan tradition, the Gigilqam are the descendants of the thunderbird. This house front was excellently painted, but has been whitewashed, owing to the misplaced zeal of a missionary. The beak was carved and fastened to the house front. (so: $\left.375^{-76}\right)$ 
In this particular case, the drawing of the vanished design enables the reader to see what it looked like before it was whitewashed: the photograph of the house front, which could not capture the almost invisible painting, is turned into a drawing, the remaining traces of the motif are exaggerated and the original design is made fully visible once again. While he acknowledged the damaging effects of historical encounters between Native Americans and missionaries on the Northwest Coast, Boas nonetheless chose not to show a "historical" and somewhat dramatic view of the whitewashed painting. Boas cared very much about the culture of the Kwakiutl Indians before their contact with "the white man", and his text leaves no doubt as to his own opinion regarding the impact of Western culture on the Kwakiutl culture. Yet documenting the artistic production of the Kwakiutl, among other aspects of their culture, remained his foremost concern, as illustrated by the ubiquitous presence in his work of drawings of the various ornaments used by the Kwakiutl. While the text goes so far as to provide the reader with a textual image of the whitewashed house, the drawing restores the original painting and provides a vivid example of ornamentation. In this specific example as in others, the drawings found in Boas' report "can be detached from the natural conditions in which their motifs are bound; they can isolate, single out, decontextualize; they can transport their subjects into different surroundings; they can take imaginary viewpoints. This makes drawings capable of conceptual idealization and abstraction; of visually presenting symbolical signification; of depicting reality beyond realism, of transcending." (Oppitz, 2001: 122)

The scientific "accuracy" of the drawing does not lie in its ability to produce a "likeness"; as in the case of the whitewashed thunderbird and whale, a truthful image would have left the reader with nothing to see other than the faint traces of an undecipherable motif. Boas does not seem to agree with a nostalgic perspective; his drawings are actively selective and interpretative. In this case, the photographic image is turned into a drawing of what is no longer visible to the human eye, which is also the most interesting thing from the ethnographer's point of view. The two media successfully complement each other: the photograph brings out the general form of the house, whereas the drawing enables the reader to see what the passage of time has made indistinct and provides a clarification of the decorative design that the camera could not achieve. In this case, the drawing can be seen as an interpretation of what the anthropologist sees, but it can only be "readable" if the anthropologist has a clear understanding of what lies before his eyes and if this meaning finds a "translation" in a coherent means of representation. Masks and other artistic paraphernalia or motifs such as the complex design found on the house front 
of the Nimkish require a deep attention on the part of the anthropologist, who must recognize and decompose the various elements of this complex art. ${ }^{5}$

Photographs prove to be no less inventive than drawings. But they address different subjects with a different approach. They contextualize rather than put an emphasis on the various elements constituting an artefact; they are holistic in respect to the object that they focus on and cannot be selective like drawings. The fact that photographs contextualize does not mean that an alteration cannot be made to them. Indeed, some critics such as Anne Maxwell have been particularly vocal on this subject. ${ }^{6}$ According to Maxwell the illustrations found in nineteenth-century ethnological publications are not valuable as primary data, because they are "untrue" to the reality of Indian life at the time. Photographs in particular have been accused of concealing the difficulties involved in, and erasing the traces of, forced acculturation and integration of Native Americans into modern life. They are too colonial, too romantic, too idealized, in a word, too ideological to be considered as "good" primary sources. Rather than pursuing this line of argument, however, I would like to focus on how such photographs received a specific treatment that tended to achieve a quality close to that of the drawings. For example, the few plates depicting men and women in the report are not captioned as "portraits" and have little to do with the numerous images of Native Americans available at the same time throughout the western territories. ${ }^{7}$ On the contrary, the photographs of single people found in Boas' report focus on the activity of the person depicted. For instance, Figure 10.3 shows a member of the Hamatsa secret society dancing. In this case, as in other illustrations (e.g. a "Chief delivering speech at festival"), the title of the illustration is generic: "Dance of the Hamatsa." Although this illustration focuses on the activity rather than the person, the rest of the legend still mentions the "grandmother" of the man

5 In the case of Kwakiutl art or Northwest Coast art in general, what appears to be an abstract design is in fact very often a stylized representation of naturalistic elements. Bill Holm suggests, following Boas' own analysis of the art of this region, that "practically no examples of Northwest two-dimensional art are realistic in the ordinary sense. The different degrees of realism in this art seem to result not from a variety of concepts of representation but from the artist's preference (more or less strictly bound by tradition) in handling the given space." (Holm 1965: 11)

6 As illustrations for his report, Boas used photographs he commissioned from Northwest Coast photographer O.C. Hastings during the Chicago Columbian Fair of 1893. See Maxwell (2002).

7 The first photographs taken on the Northwest Coast since the late 186 os were commercial, small-size pictures of Indian warriors. These "portraits" or "cartes-de-visite," as they were called at the time, fitted well with the wider vogue for mass-produced celebrity photographs that swept through the American continent. See Thomas (1981). 
appearing in the picture. Yet the general impression left on the reader is that of a generalizing image of the dancers from this particular secret society, and of their specific ornaments. It seems that most of the time Boas required that photographs be rendered as drawings - that is, selectively - in order to maintain the distinctness and clearness of the illustration. Very often details such as the background have been erased or blurred, thus making the foreground appear more clearly (Figure 11.3). In contrast to what other anthropologists were doing, who included some of his own students such as Alfred Kroeber, Boas had little interest in giving a general impression, even in the most "natural" pictures found in his report (Jacknis, 2002: $5^{26}$ ). He was very much concerned, on the contrary, with the peculiarities and the details of each ceremonial, costume, mask, cedar bark head ring, or with the gesture accompanying certain activities such as fishing, cooking, and of course dancing, etc. This reinforces the abundance of views and images, which can be at times overwhelming for the reader.

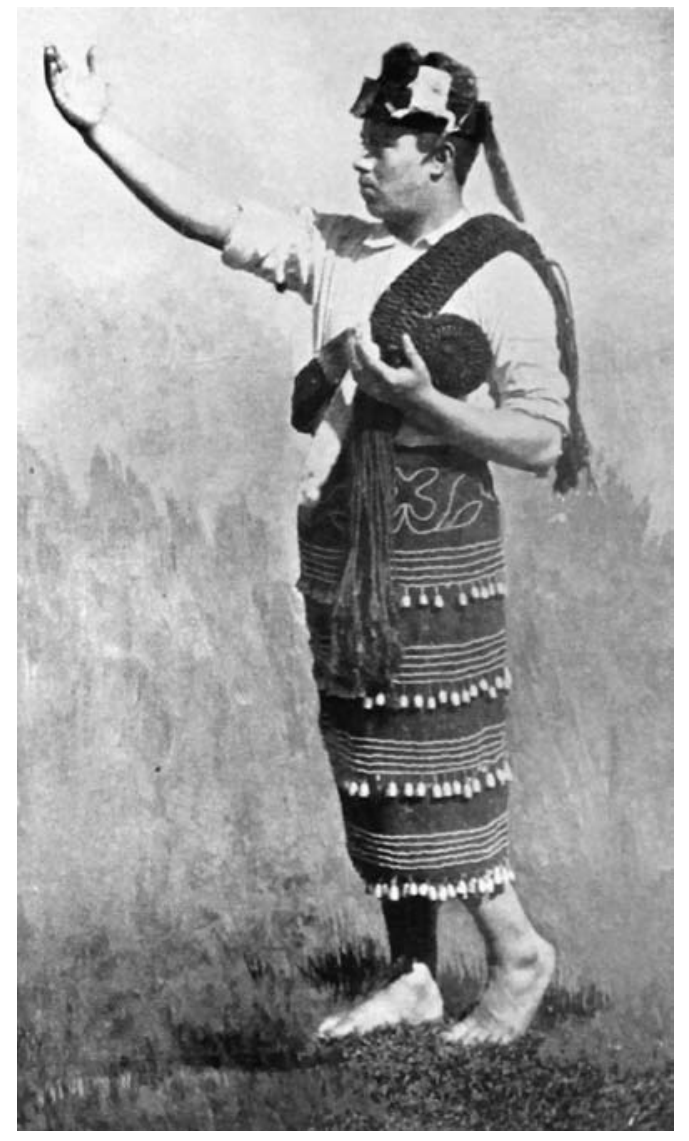

FIGURE 11.3

Plate 28 of The Social Organization is captioned "Dance of the Hamatsa. The peculiar head and neck ring of the dance were obtained from the Tlingit, his grandmother being of the Tongass tribe. From a photograph." The dancer poses on a stretch of grass, which only reinforces the artificial character of the image. In fact, this grass was that of the Chicago World Columbian Fair grounds of 1893, and the dancer was surrounded by other Kwakiutl. The "context" surrounding the dancer has been erased, and the focus is put on the gesture and the paraphernalia. 
Because of his interest in the details, gestures, and positions of each person during ceremonials or more daily activities, Boas paid a good deal of attention to the exact order in which the Kwakiutl would arrange themselves or move around. To a certain extent, the plates made from photographs can be described as real "illustrations" of the attitude of the Kwakiutl Indians. Boas regularly wrote to Hunt about his desire to receive such "illustrations" of certain specific activities, which were only available through partial textual description or stories:

I have looked over again the subject-matter of your cooking, and I find that in order to print the material satisfactorily, we ought to have illustrations showing the way the cooking is done. (...) I should like, for instance, to have a photograph of the man and the woman sitting at the hole on which clams are being steamed, and photographs showing the manner of cutting fish. It would also be well to have photographs for showing the fish as it is being cut, because it is very difficult to understand some of the descriptions of the cutting without illustration. ${ }^{8}$

This letter, written long after the publication of the 1897 monograph, reveals how much Boas relied on images and photographs to understand native cultures. More importantly, this letter shows that Boas' interest in the Kwakiutl Indians became wide and varied, and embraced all aspects of their life. Just as he believed that the best way to obtain a truthful and precise text was to receive it directly from a native speaker - in his case he had spent some time teaching George Hunt how to write and translate his own language -, Boas expected his informants to provide him with images (sketches or photographs) made by themselves in so far as they had mastered the skills necessary for doing so. ${ }^{9}$ Materials secured by the natives themselves were at the foundation of Boas' anthropology, and the fact that he applied these principles to pictures as well is in keeping with this methodology. The images of the cooking or cutting mentioned above provide much more than a visual equivalent to the text: they provide a key to the understanding of this particular activity.

The use of illustrations in The Social Organization therefore debunks the usual function of both media: drawings are often said to be about generalization, whereas photographs are said to be more specific, to do with the unique-

8 F. Boas to G. Hunt, November 22, 1907, American Philosophical Society (Franz Boas Papers, Correspondence). Unpublished archive.

9 Boas not only instructed Hunt in the writing of his own language, he also introduced him to the use of the camera. See Jacknis (1992). 
ness of one object, scene, or person. In fact, illustrations made from photographs have much in common with drawings: they must be as precise and detailed as possible, while providing a realistic dimension that drawings cannot achieve. Rather than being competing media of representation, drawings and photographs serve different purposes. While both have to maintain distinctness and clarity, photographs are more concerned with the general impression of an object and (e.g.) the contextualization (not necessarily historical or geographical) of a ceremonial or an activity. Drawings, on the other hand, have certain qualities that make them preferable to photographs in certain circumstances. Boas, for example, preferred drawings because they belonged to a graphic tradition that included geological, archaeological, and cartographic drawing. ${ }^{10}$ Yet Boas, as observed above, was not adverse to using modern techniques to record the many activities and traditions of the Indians of the Northwest Coast. Late in his career, in the 1930s, he even took ethnographic footage of dances, games and craft-making. But Boas always turned to modern mechanical devices to serve his higher goal: to observe cultural practices and record them with as much objectivity as possible. He achieved this not only by reflecting on the use of photography vs. drawing, but by using the images he produced to record more information and valuable data on the tribes he was studying. Together with the images, Boas frequently published this data in written texts. Such texts lay at the foundation of his approach to culture, an approach directly linked to the German romantic association between language and culture advocated by the likes of Johann Gottfried Herder and Wilhelm von Humboldt. The influence of this philological tradition upon Boas - illustrated in the countless books of myths and legends published by him - requires that we closely examine the relationship between images and text in the Kwakiutl monograph of 1897 .

\section{Images and Their Text}

A detailed analysis of The Social Organization reveals that text images or plates never occur without some form of citation or description in the text. Boas had always paid close attention to the writing and editing of his work and that of others. Ensuring that illustrations matched the order of the text was particularly crucial to him (Jacknis, 2002:526). In the 1897 monograph, Boas took great

10 At the time, American anthropology embraced subdisciplines such as linguistics, archaeology, physical anthropology, and archaeology. It is therefore not surprising that their methods may overlap. 
care with the layout of the images, which were not only articulated by the text through cited references, but were placed within the argumentation. If we look at the masks and totem poles, for example, we can see that they are always linked to a specific text within the general discussion, namely to a legend or tale. The corresponding legend tells the story of the acquisition of the totemic animals featured on the pole or portrayed in the mask, and of the names of the clan whose artefacts are presented, etc. The relationship between the various kinds of data collected by and for the anthropologist - artefacts, objects of art, legends, songs - seems to be a specific feature of the ethnographical methodology developed by Boas.

Many of the illustrations of masks in The Social Organization were sourced from the collections of the Ethnographic Museum of Berlin, where Boas had been working under Adolf Bastian in 1886, at a time when he made his shift from physics to ethnology. He was then in charge of cataloguing masks collected in British Columbia by Captain Adrian Jacobsen, who was an explorer and amateur collector. Boas found that there was no scientific grounding to the collection made by Jacobsen, because the masks had not been gathered with the accompanying legends - the only way, according to Boas, of understanding their meaning. Therefore, Boas' first trip to British Columbia was dedicated to recording these legends, which he succeeded in doing by showing watercolours that he himself had made of the Berlin collection to the indigenous population. His own fieldwork, and later that conducted in collaboration with George Hunt, was not only devoted to the collecting and photographing of objects, but also to the collection of native words and stories, and to obtaining the meaning of artistic materials from the native peoples themselves. Boas relied greatly on Hunt to provide him with what even the most dedicated ethnographer would only ever be able to comprehend partially: the native's point of view. In a letter to Hunt, Boas writes:

I sent you some time ago photographs of a number of large carvings which you have sent me, and which I could not identify. You have never answered my letter in regard to them. Please return these photographs to me, and say on their backs what they are. You know that I wish to have, for all the large carvings, a pretty full history.

Boas' words illustrate the demands that he often made of Hunt, here accusing him of failing to answer his questions adequately. For Boas, the photographs of carvings and posts referred to in this letter required further commentary. Images alone were not sufficient because the anthropologist needed a story to accompany them - a story which Hunt was to obtain by showing the 
photographs to the indigenous population. But Boas' exact requirements are relatively vague: "what they are," and "a pretty full history", he writes. Thus these photographs functioned as a pretext for Boas to obtain, via Hunt, any sort of story from the Kwakiutl Indians: the images were to act as a trigger for the words and to encourage the Kwakiutl to speak about their culture in general terms. While Boas was interested in obtaining the meaning of the works of art made by the natives, as his many works on primitive art undeniably suggest, it seems that he was also concerned with recording texts that he would be able to study from a linguistic point of view. The stories told by the natives, once turned into a body of texts, then became available for analysis and gave the ethnographer a unique understanding of a culture from the point of view of its members. The stories that Boas asked Hunt to obtain cannot be considered as only providing information regarding the carvings or other artefacts. They were texts to be scrutinized by the linguist. As Melville Jacob noted, Boas "was not interested in obtaining a large sample, much less the whole of an oral literature. He was concerned with supplying linguistic materials that were sufficiently varied to document the study of the language. Boas' first love was linguistic analysis." (Jacob 1959: 119-20)

This particular combination of image and text that reflected the relationship between the oral tradition and the written text, and which enabled linguistic analysis, can be seen in the first plate of The Social Organization. The plate shows a headdress captioned "Nisqa' headdress representing the white owl." On the opposite page is an explanation regarding the different materials used to make the headdress, the colours of the various parts and the size of the object. In the text surrounding the two pages dedicated to the plate, Boas gives the legend and the song associated with the headdress (see Figure 11.4). The passage begins with:

The G'ispawaduwe'da, the bear clan of the Nisqa', use a headdress representing the owl (Plate 1), surrounded by many small human heads called gyad Em Laqs (claw men). This is worn in potlatches, and commemorates the following tradition (...). (so: 324$)$

Then Boas provides the legend, music sheet and lyrics of the song. On the next page, he continues his description of the clans without any further comments on this particular tradition or headdress. In this case, the artefact and the legend are only juxtaposed - Boas does not say how the former "explains" the latter. Therefore, the legend becomes a textual element with a specific position within the general narrative of the monograph; it only makes sense in relation to the other elements of the monograph, namely the images representing 


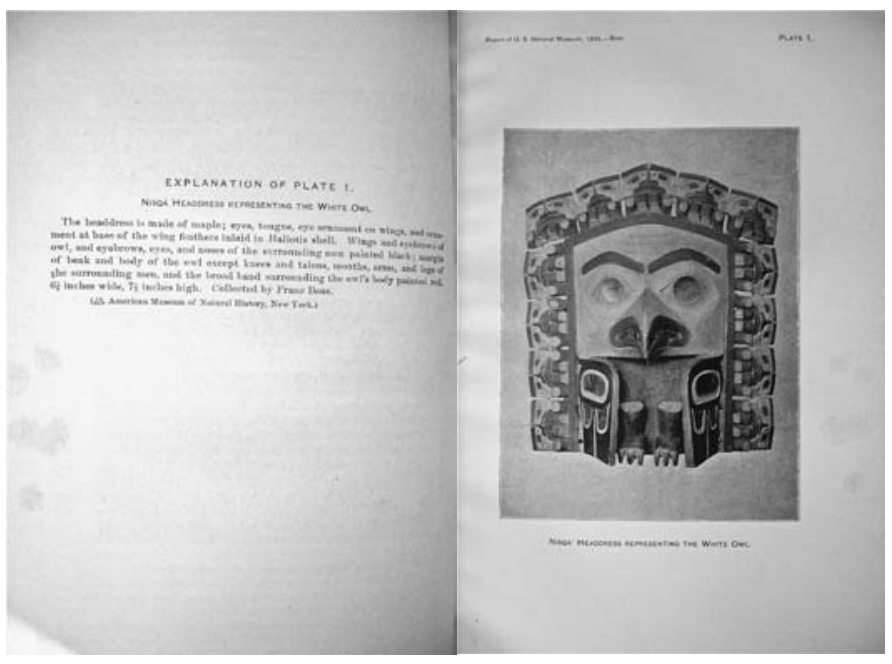

$a$

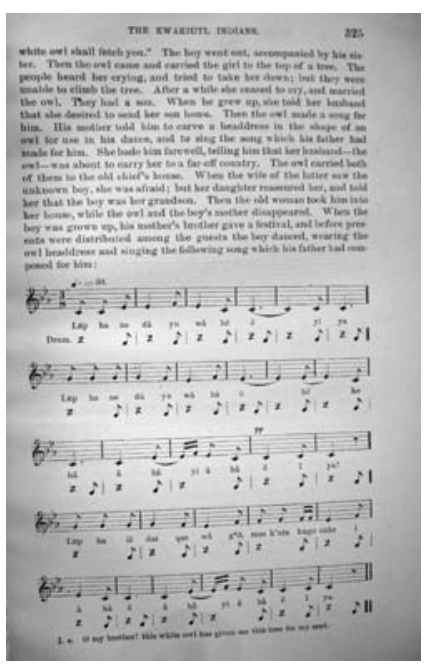

$b$

FIGURE 11.4 a) On the left is the explanation of Plate 1 of The Social Organization, with the corresponding image of the headdress representing the white owl on the right. These facing pages are inserted between $p .324$ and 325 of the report; $b$ ) This page (325 of the report) displays a combination of text and music, i.e., the song belonging to the owl's legend.

specific artefacts, music, songs, etc. The combination of these different kinds of "raw data" is a reflection, as it were, of the culture of the Kwakiutl Indians.

The anthropological image thus becomes part of a wider scientific program. In fact, it is not used as a mere illustration but it is intricately embedded within the general narrative. It leads the reader back to the text and functions in accordance with a specific legend. The relationship between the masks or the totem poles, for instance, and their corresponding legends is reflected in the layout of the book, in which images and text have been interspersed with much care (see Figure 11.4 and Figure 11.5). We could argue that the ethnographic data the reader is confronted with in this book reflects the intricacy of language, art, myths and ceremonials in the life of the Kwakiutl Indians. More importantly for us, the images, whether drawings or photographs, participate in the general process of collecting data in the form of legends and myths. As a result, it is clear that Boas intended these images to be an integral part of the content and design of his monograph from the outset.

Yet, though images were an integral part of the monograph, the fundamental idea that language was at the core of cultures ensured that text and language remained the primary focus for Boas. This was somewhat in contradiction with others, such as Edward S. Curtis, who were working in the same region of 

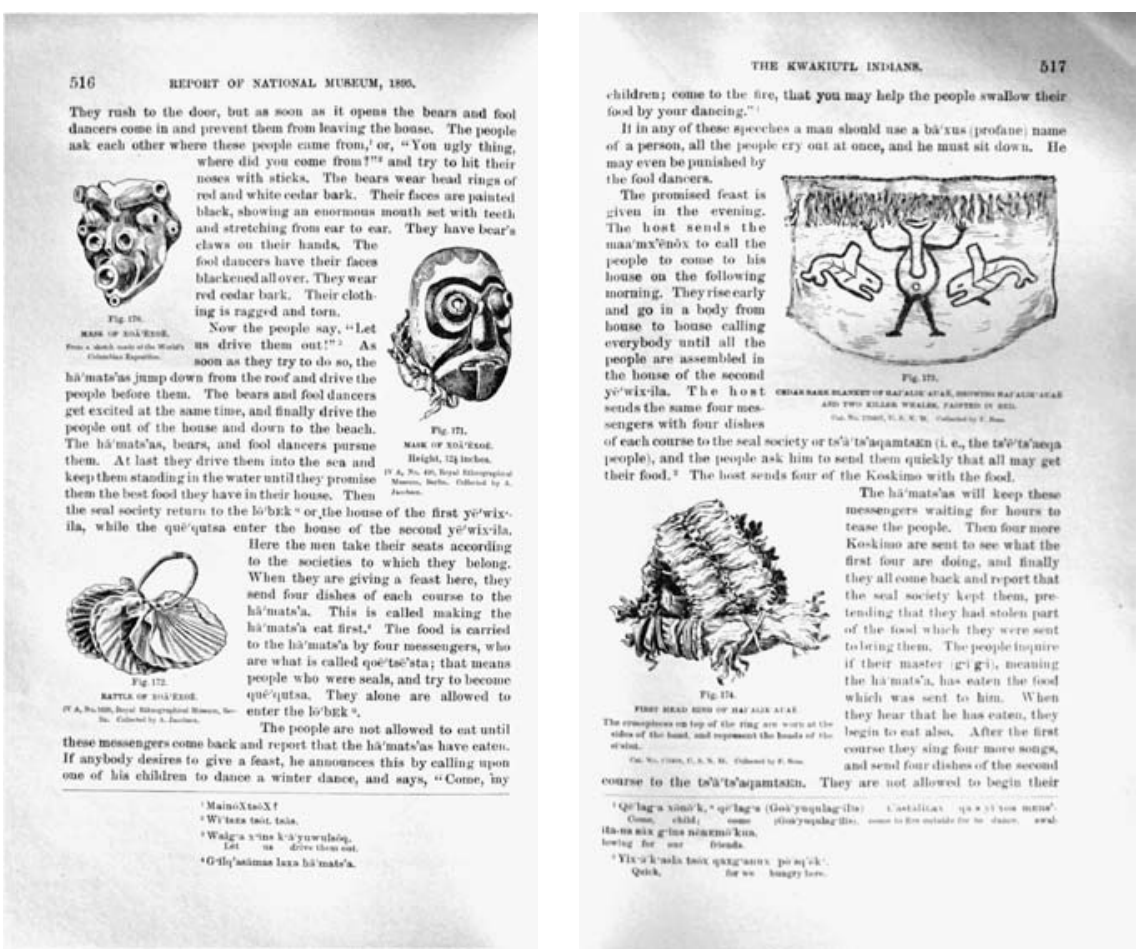

FIGURE 11.5 An example of the combination of ethnographic data. Here are two pages $(516$ and 517) where no less than four drawings, representing two masks, a rattle, a blanket and a head ring, are reproduced within the text.

the world at this time. Between 1907 and 1930, Curtis, who had no scientific background but was a professional photographer, undertook a vast and encyclopaedic publication of no less than twenty volumes entitled The North American Indian, published between 1898 and 1930. Curtis was engaged in a vast program aimed at bringing back the most "authentic" images of the Native American cultures, rather than texts. He therefore spent a good deal of time re-creating scenes of Indian life, staging his sitters, and dressing them in ancient clothing (Thomas, 1981: 79). Curtis worked according to the Victorian tradition and taste for the accumulation of knowledge, embodied in the volume of his (visual) project. Franz Boas, as a strong empiricist, also believed in collecting an extensive corpus of ethnographic data from native texts to actual artefacts and images. He was not unfamiliar with the quest for the most "authentic" traces of primitive cultures, but he viewed Curtis' work as largely nonscientific. George Hunt, who had been working for Curtis as well, shared Boas' criticism of him and was also heavily critical of his approach, namely his 


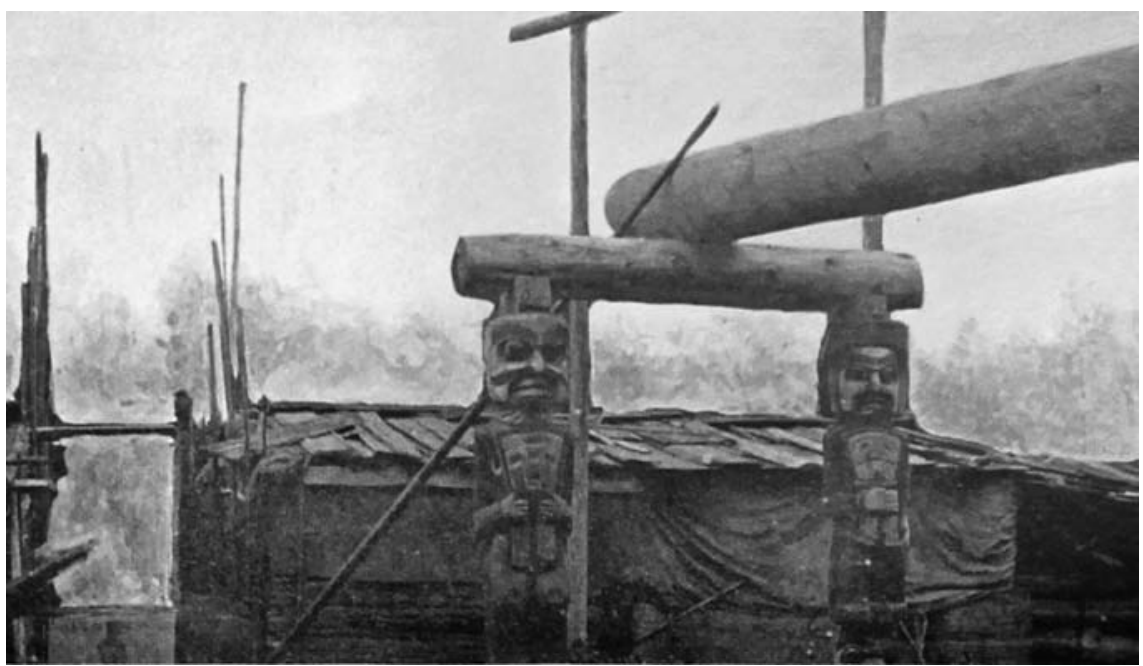

FIGURE 11.6 Plate 16 of The Social Organization represents houseposts in the shape of animals holding coppers. The background of the village has been blurred, thus focusing the attention of the reader on the posts themselves rather than on their environment or any other irrelevant element that could be seen on the picture.

over-aestheticization and romanticization of the Kwakiutl culture. Hunt once wrote to Boas concerning a picture of his wife dressed as though for a marriage, which had been taken by Curtis: "He Dont know what all the meaning and the story of it. For on that Picture you cant see the four carved Post under it."11 Curtis tried to keep a strong conceptual control over his photographs. In addition to a dramatic imagination, this produced an aesthetic rather than scientific approach to Indian cultures. In contrast Boas was more concerned with the scientific validity of the material represented in the illustrations than with creating an extensive visual survey of the "vanishing" cultures of the American West. In this respect, Boas it seems cared about the modern medium of photography only in so far as it could contribute to his scientific work. A comparison of Curtis' picture of a Kwakiutl house (Figure 11.7) and Plate 16 of The Social Organization (Figure 11.6), which both show two house posts and the beams of a native house, reveals striking differences between Curtis and Boas in terms of their visual representation and understanding of the same culture, although these photographs were not taken at the same time.

11 G. Hunt to F. Boas, May 4, 1920, cited in Jacknis (1992) 145. As Jacknis noted, "not only did Curtis not photograph the most important elements according to a Kwakiutl viewpoint, but, unlike Boas, he was interested principally in visual effect (...)." (Ibid.) 


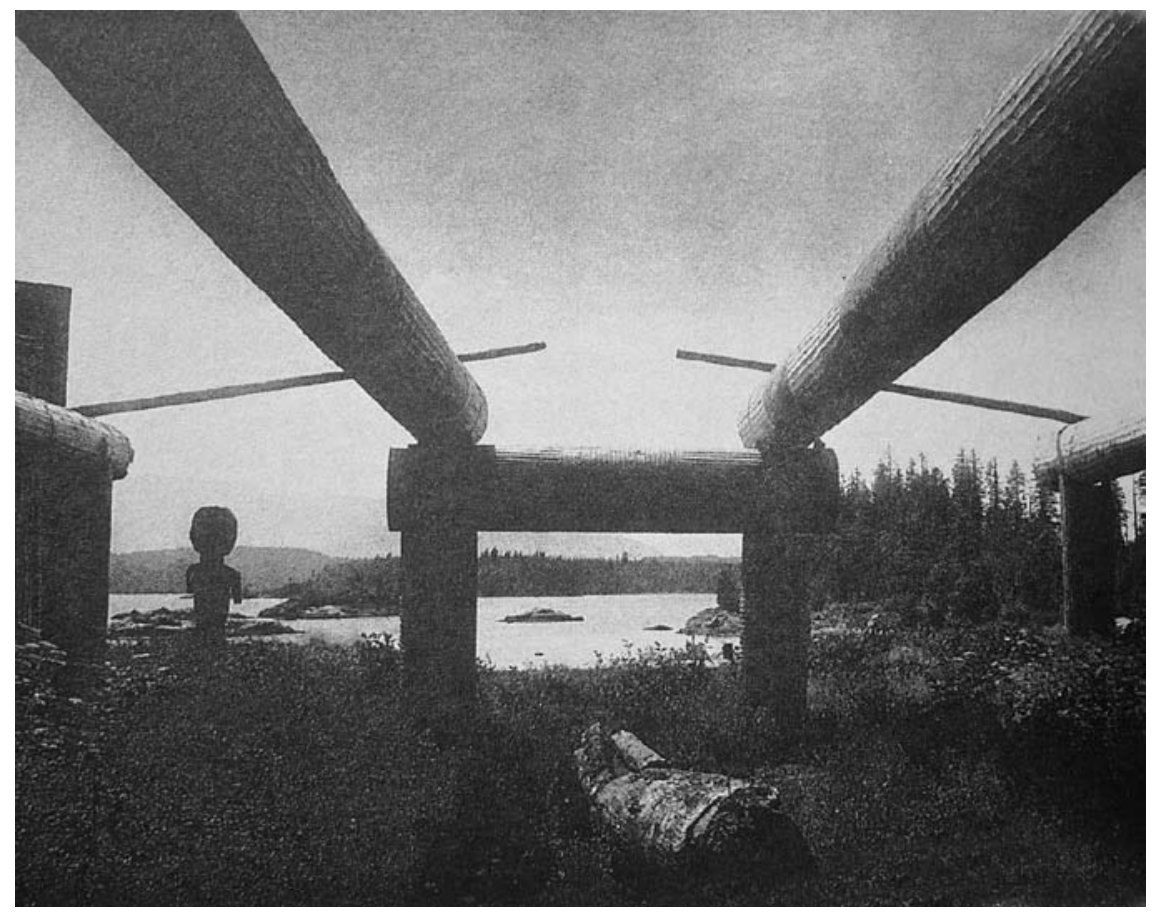

FIGURE 11.7 Edward S. Curtis' Kwakiutl house-frame was published in vol. Vof The North American Indian, 1915. Although the title suggests that the image focuses on the architecture of the typical Kwakiutl house, the "romantic" subjectivity of the photographer is evident in the dramatic framing of the photograph in which the posts of the house have been used to draw the viewer's attention to the background images, rather than to the house-frame in the foreground.

The neutral black-and-white image in Boas' text stands in clear opposition to the sepia tones of Curtis's picture which immediately suggest a sense of nostalgia based upon the popular ideology of the Vanishing Indian. The image of Indian cultures as "fading" was in itself not a new idea in America at the beginning of the twentieth century. Indian cultures were in disarray and many peoples had almost disappeared. Curtis' mission, as he understood it, was to depict "all features of Indian life and environment, types of the young and the old, with their habitations, industries, ceremonies, games and everyday customs" (Curtis, 1907: xiii). With his gigantic work, consisting of twenty volumes, Curtis wished to collect the traces left by the disappearance of the American Indian and to build an American monument not only to him but also to America's past (Arrivé, 2007). Boas, as an immigrant with no particular emotional or cultural links to American history, was probably less likely to view Native American cultures as Curtis did, although he did manifest his concern for the 
preservation of Indian cultures. The picture from Boas' work instead focuses on the details of the construction, the architecture of the house and the carved posts holding the supporting beam. As in many other cases, the background has been blurred, rather roughly, in order to focus the attention of the viewer on the foreground and, perhaps, to eliminate any trace of the most recent transformation in the native way of life. In any case, the focus is put on the architectural detail and function of the two houseposts supporting the large beam above them. Despite its title, Kwakiutl House-frame, Curtis's image is less centred on the concrete depiction of the architecture than on the landscape that surrounds it or, to be more precise, that opens-up in front of it. The remaining poles are directed toward the sea and the carved animal, on the left hand-side, turns its back to the viewer, facing an ever-lasting sunset on a deserted village. The position of this statue, with its active gaze in the distance, makes it alive with nostalgia and, perhaps, sadness. Curtis undoubtedly wanted these feelings to be transferred from the statue to the viewer. The frame of the photograph itself encloses the internal frame created by the beams at the centre of the photograph, which draws our perspective towards the horizon, suggesting a sense of loss as well as of "infinite patience and acceptance." (Thomas, 1981: 79). Such a dramatic staging is completely absent in Boas' picture, where the absence of a background decontextualizes the image and prevents any comment on the passage of time. In this case, the viewer is cast in the role of a distant observer, left to examine the totem poles and their carvings from a dispassionate viewpoint. In sum, whilst Boas was far from indifferent to the purpose of "salvage ethnography," he tried not to provide his reader with images that could only reinforce a romantic vision of the Indians or prompt a meditation on disappearing cultures.

\section{Bibliography}

Arrivé, M., "Communication in Silence? Relational Interstices in Edward S. Curtis's Portrait Photographs" (The North American Indian, 1907-1930), in Culture, Language and Representation 4 (2007), pp. 9-32.

Boas, F., "The Social Organization and the Secret Societies of the Kwakiutl Indians," in Report of the U.S. National Museum for 1895 (1897), pp. 311-738.

Cole, D., “The Value of a Person Lies in His Herzensbildung': Franz Boas' Baffin Island Letter-Diary, 1883-1884," in Observers Observed. Essays on Ethnographic Fieldwork, ed. G.W. Stocking, Jr. (Madison, 1983), pp. 13-52.

Curtis, E., The North American Indian, volume I (New York, 1907).

Holm, B., Northwest Coast Indian Art. An Analysis of Form (Seattle, 1965). 
Jacknis, I., "Franz Boas and Photography," in Studies in Visual Communication 10-1 (1984), pp. 2-6o.

-_- "George Hunt, Kwakiutl Photographer," in Anthropology and Photography, 1860-1920, ed. E. Edwards (New Haven, 1992), pp. 143-51.

- - "The First Boasian: Alfred Kroeber and Franz Boas, 1896-1905," in American Anthropologist 104-2 (2002), pp. 520-32.

Jacobs, Melville, "Folklore," in The Anthropology of Franz Boas. Essays on the Centennial of His Birth, ed. W. Goldschmidt, American Anthropological Association, Memoir 89 (1959), pp. 119-38.

Lehni, C., "De l'exploration au récit grand public. Usages de l'image dans Canyons of the Colorado par John Wesley Powell," in Etudes photographiques 18 (2006), pp. 72-95.

Maxwell, A., "Montrer l'Autre: Franz Boas et les sœurs Gerhard," in Zoos humains, ed. N. Bancel et al. (Paris, 2002), pp. 331-39.

Oppitz, M., "Drawing or Photograph. Questions on Ethnographic Illustration," in Robert Powell's Himalayan Drawings, ed. M. Oppitz (Zurich, 2001), pp. 91-123.

Peterson, Nicolas, "Visual Knowledge: Spencer and Gillen's Use of Photography in The Native Tribes of Central Australia," in Australian Aboriginal Studies 1 (2006), pp. $12-22$.

Prins, H., "Visual Anthropology," in A Companion to the Anthropology of the American Indians, ed. T. Biolsi (Oxford, 2004), pp. 506-25.

Sandweiss, M., Print the Legend. Photography and the American West (Yale, 2002).

Thomas, A., "Photography of the Indian: Concept and Practice on the Northwest Coast," in $B C$ Studies $5^{2}$ (1981), pp. 61-85. 